\title{
Towards a Theological Anthropology of the Digital Age
}

Some Introductory Remarks

\author{
Gemma Serrano \\ Professor of Theology, Faculté Notre Dame, Co-Director of the Department \\ "Humanisme numérique", Collège des Bernardins, Paris, France \\ gemma.serrano@collegedesbernardins.fr
}

\author{
Alessandro De Cesaris \\ Post-doc research fellow, University of Turin, Turin, Italy \\ Visiting research fellow, Department "Humanisme numérique", \\ Collège des Bernardins, Paris, France \\ alessandro.decesaris@unito.it
}

\begin{abstract}
The paper aims at providing some introductory insights in the project of a theological anthropology of the digital age. The objective is to show that theological anthropology can help us gain an original and valid perspective on the technological transformation we have been experiencing during the last few decades. In order to do so, it is not enough to underline the analogy between some sources of the Judeo-Christian tradition and some aspects of the so-called digital culture. Instead, the objective is to show that theology can offer some theoretical instruments able to offer a deeper insight in our condition. The paper starts from the notion of finitude, interpreted as a blessing and not as a "limit" of our nature. Through the distinction between Promethean and Epimethan approaches to technology, the text focuses on three core aspects of human finitude: corporeality, inner life and otherness.
\end{abstract}

\section{Keywords}

digital - anthropology - finitude - Epimetheus - Prometheus - interiority - body 
Thinking about theological anthropology's possible contribution to the debate on the human condition in our era, in particular after the so-called "digital turn", ${ }^{1}$ is quite a challenge. At a first glance, it seems in fact that an actual understanding of digital culture is only possible from a post-religious, to some extent even post-spiritual point of view.

Of course, the theological vocabulary - and the study of theology in general - is very widespread in the field of continental philosophical and cultural studies, particularly thanks to that current usually called "political theology", a current started in the German debate that flourished in France and in Italy during the last half century. ${ }^{2}$ The starting point of this approach, as we know from Carl Schmitt's foundational writings, is that the vocabulary of politics basically consists of secularized theological terms. It would be easy to transform this thesis in a general statement about our culture: The vocabulary of Western culture is nothing but a secularized theological lexicon. ${ }^{3}$ Following this idea, a theological anthropology of the Digital would be in the first place a philological operation aiming at retracing, behind the secularized façade of our present hypermodern human condition, the theological ground of its origins.

This operation is not without value, and this is evident if we think about how our culture metabolized the novelties produced by the social implementation of digital media: The life of contemporary man has its own digital liturgy, its awe and idolatry for new devices, even its own eschatology. ${ }^{4}$

Yet, the effort to think a theological anthropology of the Digital cannot be limited to this genealogical operation, since this kind of work still operates on the niveau of analogy. The anthropological model we would like to propose

1 For a general introduction to the topic of digital transformation from the standpoint of Humanities see Floridi, The 4th Revolution; Doueihi, La Grande Conversion Numérique.

2 Regarding the development of the debate concerning political theology in Italy, Roberto Esposito has created the term "Italian Thought" in order to designate the specific intertwine of politics, history, theology and philosophy in many Italian thinkers (for instance Giorgio Agamben, Massimo Cacciari, Mario Tronti and himself). See Esposito, Living Thought and Esposito, A Philosophy for Europe. A very good critical examination of the current named "Italian Thought" has been offered by Pier Paolo Portinaro. See Portinaro, Le Mani su Machiavelli.

3 The main reference is of course Schmitt, Political Theology, pp. 36-52. For an application of this principle to economy see Jourdain, Théologie du capital.

4 The eschatological and quasi-religious dimension of digital culture is clearly recognized by many scholars. See for instance Harari, Homo Deus, pp. 302-326; O'Connell, Being a Machine; O'Connell, Notes from an Apocalypse. 
in this paper is somehow more ambitious: We would like to show that theological anthropology, as a theoretical way to understand human condition, can help us gain an original and valid perspective on digital culture. "Original and valid", here, refers to two kinds of results: In the first place, we will try to offer a descriptive theory of human condition that will be able to identify details and aspects still unseen, because they cannot be grasped by purely secular approaches. Secondly, this theory should lead to the possibility to gain a new kind of wisdom when it comes to normative ethics. The final aim is to provide an understanding of digital technologies from the anthropological standpoint that will be able to guide us wisely and consciously in the political and social struggle concerning the way digital media are developed, implemented and used.

In this general framework, of course, a preliminary definition of what we mean with the term "technology" is required. We would like to point out that technology cannot be reduced to the domain of "instruments", nor to a specific set of practices ("techniques") we use in order to act in the world and among ourselves. Technology is not just the application of scientific knowledge but rather, and much more deeply, the kind of knowledge and expertise that allows us to interact with the world and with others. Technological objects are the concretisations of this kind of skill. They make it possible for us to create relationships with each other and with the environment. ${ }^{5}$

Now, what are the distinctive features of a theological-anthropological perspective on human being? We would like to highlight two elements.

\subsection{Finitude}

The human being is finite. The analysis of human finitude requires us to investigate multiple dimensions: creaturehood, a temporality structured on the different stages of life and finally death, sensuousness as privileged horizon of our relationship with the world and amongst ourselves. All such features point to corporeality as the dimension most proper to humans: The human body is created, marked by time, mortal, sensuous and thinking. The complex dynamics of the body and of its affections determine our human way of being.

5 Eric Schatzberg (Technology: Critical History of a Concept) has widely shown that the term "technology" in the English-speaking culture has had a vast variety of meanings, and that it is one of the most ambiguous terms in the Western vocabulary. The main reference for the idea of technology we are proposing here is the work by Gilbert Simondon (see for instance Simondon, Du Mode d'Existence des Objets Techniques; Simondon, Naissance de la Technologie, p. 131). 


\section{$1.2 \quad$ Openness}

In order to identify the specificity of human finitude, it is important to connect it to the notion of openness. Part of the tradition has interpreted this openness as a form of transcendence, namely through the reference to a "world behind the world" or to a "superworld". The introduction of such transcendent dimension entails a new kind of polarity between human and non-human condition. Some scholars, such as Karl Jaspers and Jan Assman, ${ }^{6}$ tried to identify the precise historical moment in which some civilizations have developed a reflexive consciousness of this transcendence, but this transcendence is - at least implicitly - a structural feature of human life since the beginning. This does not mean understanding the human condition as opposed to some sort of "inhuman" or "superhuman" condition. On the contrary, the tension between finitude and infinite, part and whole, perspective and absoluteness, corporeality and spirituality, interiority and world, becomes a constitutive element of our way of inhabiting the Earth. It is only thanks to this tension that humanity can live through the modalities of inhabiting, thinking, believing, desiring: Openness is a necessary condition for these kinds of experiences. ${ }^{7}$

\subsection{An Hermeneutics of Finitude}

These two elements, taken together, determine the structurally hermeneutical nature of human condition. Human life is expression, and as such it is not a monolith, but must interpret and re-interpret itself constantly, keeping the tension between where it is and where it could be. ${ }^{8}$

This means that stating the finitude of human being, from the perspective of theological anthropology, does not entail any reference to something missing, to a curse or a sickness that humans should somehow find the way to "heal". ${ }^{9}$ Understanding finitude as a kind of shortage is only one of the many possible ways to approach the analysis of human condition. Another possible way is the one that identifies finitude as the specific - positive - determining feature of human being, as its own blessing.

These two ways to understand finitude are at the basis of two opposite attitudes towards technology, which are at the same times two attitudes of

6 The reference is to the notion of "axial age", coined by Karl Jaspers (The Origin and Goal of History, pp. 1-21). See Bellah-Joas, The Axial Age and Its Consequences; Assman, Achsenzeit.

7 For instance, Agamben's magistral meditation on the notion of "openness" with relation to the concepts of "world" and of "animal" implies the theological question concerning the difference between man and God. See Agamben, The Open, p. 16.

8 The reference here is to Herder's Anthropology, as it is presented by Charles Taylor. See Taylor, The Language Animal.

9 See Gehlen, Man, p. 27. 
technology itself. To summarize, we could identify them as a Promethean and an Epimethean attitude. The reference to the characters of Prometheus and Epimetheus is of course very old, and in the 2oth century it has been the object of many studies on the relationship technology and human condition (in particular by Bachofen, Illich, Schmitt and Stiegler). ${ }^{10}$

We could briefly depict the Epimethean attitude by saying that it refers to a conception of technology as "care for finitude". Humans live their own finitude, finitude determines the space of their action and of their being. Technology is the way how they shape this place, how they inhabit it. Technology is the specific modality of human finitude.

On the contrary, the figure of Prometheus emphasizes the tension between technology and finitude: Technology understands itself - and is understood as the overcoming of finitude, as a "solution" to it. By giving technical expertise to men, Prometheus aims at minimizing the difference between human and divine. Günther Anders' reflections about "promethean shame" immediately come to mind:11 Humans feel envy for the machine, because machines overcome the human condition, their weakness, finitude, temporality.

It is not difficult to show how the so-called "digital turn" has awakened both these attitudes. A very common point of view - that culminates in the transhumanist position - sees in digital technologies a new chance to fix some flaws of the human species. ${ }^{12}$ It is also easy to connect the distinction between Epimethean and Promethean attitude to the distinction between continuist and discontinuist stances. Seen through the lens of Prometheus, the digital turn appears as a revolution capable of modifying human nature forever. In this essay, we would like to defend a continuist - and thus Epimethean approach: Despite its specific features, its promises and its potentialities, the digital world is not radically different from the pre-digital one. It just describes a new trajectory; it offers new ways to be in the world and to relate to our own human condition.

The question we would like to ask is thus the following: How do digital media influence and shape the structural traits of human condition we have just presented? We are going to answer this question by taking under consideration three constitutive elements of human being: corporeality, interiority and alterity. We would like to argue that theological thought has always offered a very rich and complex perspective on these aspects of human life, and that a

\footnotetext{
$10 \quad$ Illich, Deschooling Society, pp. 105-115; Stiegler, Technics and Time 1, pp. 183-203.

11 Anders, Die Antiquiertheit des Menschen.

12 The classic reference is Ray Kurzweil, The Singularity is near.
} 
theological anthropology offers a very interesting source of theoretical instruments in order to understand our relationship with technology.

\section{$2 \quad$ Corporeality}

The body is the starting point of our research. Putting the bodily dimension on the ground - and at the core - of a theological anthropology of the Digital has many repercussions on our general project. We will highlight some.

First, it means stating that humans are primarily finite because they are bodies. It is the body that makes the humanity of the human, it is the body that determines the specific modalities of its finitude. These modalities are not static, but rather dynamic, or plastic: They respond to the way we use our body, far from any abstract separation between body and spirit. The human spirit is modelled according to the human body, our minds and our feelings start from the body and in the body find their reason.

Secondly, this research will be shaped in a concentric progression, and not as a juxtaposition of topics. By stating that corporeality is the core of our discourse, we are also implying that the following section, interiority, will have to be understood on the basis of our conception of the body. Equally, our analysis of otherness will be based on the previous two sections.

Moreover, starting from the body means stating that anthropology is primarily an aesthesiology. It is a theory of the senses, a research that shows how the human body - the system or the assemblage of its organs - reshapes itself after the technological evolution. This means, in the first place, that technological evolution is interpreted also as a shift of our sense paradigm. Every technology determines a certain economy of the senses, a new balance between human faculties.

The anthropologists of technology have often focused their attention on three elements that are fundamental for the history of hominization. These elements belong to every age and constitute the aesthesiological core of the human way of being into the world: The first is sight, in particular the correlation between hand and eye. ${ }^{13}$ Then there is the voice and hearing, and thus the set of sounds that belong to the community, from tribal rhythms to language. Finally, the skin, or the many ways we create haptic membranes between us and our environment (fashion and architecture are some examples). Modernity has been an age eminently dominated by sight. With the digital age we could assist to a reconfiguration of our senses that puts touch at the core

13 See Plessner, Anthropologie der Sinne, Chapter I. 
of our life experience. Haptic intelligence is studied in relationship to virtual reality, while technology becomes wearable and touchable. ${ }^{14}$

Digital media are becoming the environment we are immersed in. Our relationship with them is tactile before being visual or acoustic. There is a strange analogy between digital media and tactility: our tradition understood touch as a sort of "common sense", as a ground sense for all the others - contact is the basis of every kind of feeling. In the same way, digital media allows a reduction ad unum of all other technologies, operating a fusion between biotechnologies, engineering, information technology, hard sciences, philosophy and human sciences. Through domotics and wearable technologies, digital media are becoming our second skin.

Another crucial aspect, that we must consider, is that when we talk about "aesthesiology" we do not refer to a somehow passive dimension, to human "receptivity" through the senses. Humans have an active - better, an interactive - relationship with technology, which gives form to the complex connection of individual, social and technological environment and natural environment. If our anthropology of technology starts with the body, this means that digital technologies determine a particular form of our experience of the world, of our capability to sense the environment. Digital media reshape our sensuous relationship to the world, our perception, our reactivity to stimuli.

Secondly, digital technologies also entail a particular form of interaction with the world. Our sensory reconfiguration is also determined through a set of body practices, of gestures and habits. Technology is not only something that surrounds us, it is primarily something we do and something we are.

A very ancient and respected tradition has interpreted the relationship between humans and technology through the notion of "habitus", developing a theory of the so-called "second nature" that is based on the idea of habit. Humans acquire acquaintance with their own body, with objects and devices, with the social and natural world. They do so through training, with repeated exercise, turning a new behaviour into something "natural" and somehow immediate. The generation of habits is at the same time a liberation and an enslavement: it allows us to perform complex operations without even thinking about them, saving our mental and physical energies for other operations. It is also a form of slavery, because the acquired behaviour becomes an automatic response that leaves out the possibility to choose otherwise. This

14 Lanier, The Dawn of the New Everything; Jones, Haptics. 
automated behaviour can turn into a routine of practices, gestures and even thoughts that are performed without being fully conscious of it. ${ }^{15}$

This paradoxical nature of habit has been analyzed in many different ways throughout the history of Western thought. It must not lead to a sort of technological determinism: The power of our bodies relies in their capacity to reset their structure, to reshape their habits. ${ }^{16}$ Again, bodies are finite. They do not have countless potentialities. The spectrum of possibilities of our bodies is co-determined by technologies, by the objects that extend our limbs but also by the practices that give them form. This spectrum, however, is not fixed: Humans have the chance to think new rhythms, new practices, new rules for their own acting, and by doing so they remodel their bodies and modify the modalities of their relationships with the world.

This ability to reset the features of our bodies is also a consequence of our ability to know our own bodies, their rhythms and specificities. The history of bodily practices is also a history of the knowledge of the body, a knowledge that is never complete because it leaves space for unexplored possibilities and unexpected weaknesses. These potentialities are also the reason for the tension between nature and technology, between our bodies and our technological prostheses.

The history of technology is also the history of the gap between machines and body, as witnessed by the movie "Modern times" by Chaplin. The bitterly/ comic effect of the movie is generated precisely by the almost impossible adaptation process through which the worker gets used to the rhythm of the machine. Today, it seems that the relationship between technology and humans goes in the opposite direction: The rhythm of the machine is synchronized with ours. Digital devices are designed to adapt themselves perfectly to our schedule. Such level of technological design is the consequence of the extreme knowledge of the human body we have acquired in our era.

The body has become visible, its rhythms are known, analyzed, compared, shared with others. The data collected through the analysis of these rhythms are valuable information for insurance companies, they become the source for a new kind of immediate and adjourned medical memory, but they also open the possibility for sharing and supporting each other. Until a few years ago, measuring blood pressure or heartbeat rates was something only the physicians

15 The notion of "second nature" has a huge and complex history that starts with Greek philosophy and ends up in contemporary sociology (in particular with the works by Pierre Bourdieu) and neurosciences. See Bertram, Two Conceptions of Second Nature; Sloterdijk, You Must Change your Life, pp. 16o-189.

16 On this topic see Smith-Marx, Does Technology Drive History? 
could do. At the same time, the control of bodily rhythms was included in a general path of spiritual ascesis. Today our bodies are so transparent, so visible to us through diagrams, statistics, notifications and other data, that the "discovery of the self" seems to be a very simple task. ${ }^{17}$

Living hand-in-hand with digital devices, our self-discovery relies on the hyper-focalisation on physiological, cardiac, digestive, emotional events. The digital environment is part of our own bodies, together with our skeleton and our blood. It becomes a second skin. Long ago media studies identified the city and the house as extensions of our own skin, emphasizing their tactile function - regulation of body temperature, defense from enemies and from weather. Nevertheless, before our hypermodern times this second skin was structured as a series of concentric spaces: The room we grow up in, our home, our neighbourhood, our city. Today this distinction is no longer present, and the digital environment enters in a sort of complete symbiosis with the individual body. The access to the natural rhythms of our bodies, the slow and effortless training through which we learn how to co-exist with our devices, all this contributes to the experience to feel at home in our completely digitalized environments, an experience of comfort and safety generated by the absolute control and knowledge of what once was hidden. At the same time, nevertheless, this experience obliterates the distinction between private and public, creating a uniform space where the body is regulated, measured, modified. The digital environment determines the rhythms and the gestures of the body during each moment of its existence, ignoring the difference between work, entertainment, rest, sleep. This is the main effect of the "datafication" of our existences. ${ }^{18}$

The body's new visibility takes the form of a new cadence, Mark Zuckerberg's "unsettling dream": We are finally leaving to the algorithms calculating our tracks the task to give us the measure - namely the size, but also the rhythm and the criterion - of our own existence. The measure of our meals, of our rest, of our sickness, of our emotions. They do so with push up notifications, pressuring us more and more frequently and noisily, in order to force us to keep track of their time. This is the scary and somehow already real vision that allows technical temporality to crash us. ${ }^{19}$ An anaesthetic danger awaits us in

17 For an introduction see Fairhurst, Biometrics, and Neff-Davus, Self-Tracking.

18 Cukier/Meyer-Schönberger, Big Data, p. 71.

19 See for instance Alexis Madrigal's article Zuckerberg's Dream published on The Atlantic. Another interesting source for this topic is the seminar 'Habiter' organized by Louise Merzeau at the Collège des Bernardins in 2015 . 
this uniform environment, where we are forced to measure our time and to obey all schedules.

The question is thus the following: Digital technologies allow a new confidence with the quantifiable aspects of our bodies, but does this knowledge coincide with the kind of knowledge we are able to grasp through introspection? How can we conjugate this knowledge with bodily freedom? How can we imagine the creation of new body practices in a context like this?

The Christian ascetic vocabulary has the Latin word discretio, that translates two Greek words, diakrisis (discernment) and metron (measure). The idea of measure implies beauty, prudence, harmony, moderation. We think that the Christian notion of discretion could be a mediating factor, a way to reach a balance between a measure that forces us to follow a cadence, a visibility that tells us about our own rhythms and the freedom we reach through repetition. How can we describe a just measure at the core of the various activities that form our life, and in the context of the new self-governance allowed by our new self-transparency?20 We live in an indiscreet time. The lack of discretion of the digital age is precisely the lack of temporal and spatial limits that granted the gap between public and private, social and individual. In an indiscreet time, the body is always subject to the temporality dictated by technology, just like our inner life is immediately identified with social life.

\section{3}

\section{Inner Life}

The spatial metaphor of interiority entails some polar oppositions: inside/ outside, internal/external, private/public. Such oppositions are associated with descriptive conceptual couples: substance/mask, invisible/visible, opaque/ transparent, own/common, unconscious/conscious. In the digital environment, however, such elements present some different traits. We would like to resist the temptation to describe our age as the age of the "disappearance" of interiority. We are much more interested in formulating our question as follows: How has interiority changed after the diffusion of digital media?

Another mistake that we must avoid is to consider the inner dimension as a protected space, separated from the external one. The oppositions we have just recalled could reduce some complex relationships - such as those between

20 It is important to remark that transparency is not just a feature of the public space, as Gianni Vattimo has argued in his famous study on the Transparent Society. Digital technologies give us primarily the impression to be transparent to ourselves. See Vattimo, The Transparent Society. 
spiritual and worldly, sacred and secular, thought and matter - to the distinction between inside and outside. On the contrary, it is of fundamental importance to understand that interiority is a category elaborated in order to codify a specific set of social practices. We do not use this word to describe what is invisible or unintelligible, but rather to refer to a set of practices that interact with the social texture.

As we said, speaking about interiority means in the first place speaking about corporeality, and thus speaking about space and time. The aesthesiological foundation of our theological anthropology of the Digital also refers to Kant's a priori forms of intuition, but takes away their a priori character, and understands them as plastic dimensions that can be shaped and reshaped on the social, cultural, political level. Interiority is not a category of spirit as separated from the body, but rather responds to a specific bodily practice, to a modality of locating ourselves in space and in time. It is a way of using our senses and of perceiving the distance between our bodies.

Media theory has linked the birth of "interiority" with the practice of silent reading and writing. ${ }^{21}$ Interiority starts with writing. A strange irony connects the most revealing practice of inner life - that of the private diary - to the practice of blogging, the most widespread form of public writing today. However, this connection allows identifying a crucial element. The dimension of interiority has never been connected to a somewhat obscure and deeply hidden space, but rather to a modality of manifestation. Interiority - just like intimacy - is a space, a mode of expression. Inner life has always been delimited in space and in time: in time, with the use of ephemeral supports - King Midas' whisper - and in space with the use of media that had a limited range.

Today we are not witnessing the disappearance of inner life, but rather the emergence of new forms of individual and political representation and manifestation of this life. These forms use new media, which are much less limited in space and time, but they also feature different objectives and modalities.

The paradigm of interiority shows itself through the vast variety of masks at our disposal in the form of identities and avatars. There are many different ways of narrating ourselves on the web, starting from the autobiographic practice of the selfie, up to the many forms of shared communication and content production. The notion of a multi-faceted and multi-layered self is not a novelty of the digital age. On the contrary, modernity found its own basic structure in the differentiation of the many identities of each individual, who is father and lover at home, professional at work, believer in church. In the digital age, however, the delimitations that kept these different identities separated melt

21 See for instance Ong, Orality and Literacy; Havelock, The Muse Learns to Write. 
away, and the versatile identity of the I expresses itself on platforms where everything is kept together, overcoming the traditional distinctions of modernity: The digital user is producer and consumer, spectator and creator, observer and observed, private and public.

Digital life entails a new special intertwining between private and public dimension. Every aspect of life is invaded by a never-ending practice of selfnarration. We witness ourselves by producing our own story every moment, by selecting, modifying, literally narrating ourselves to a public made of people who are doing the same thing. These self-narratives are marked by our desire to be visible, by the rule of transparency and the desire of authenticity. We want to be seen by others, we want to see them and trace them. In this way we share and show images and words from our happy and sad moments, telling to everyone how we feel, whether we are shy or expansive. We constantly share with the world our boredom and our euphoria, our truths and our lies.

Introspection is staged, it becomes public. There has always been an "expressive" dimension of introspection. Inner life is, in fact, already a social practice; it is a way of showing ourselves, a way of making experience of the world and of relating to it. Nevertheless, we are witnessing the implosion of those barriers that used to mark the difference between inner and public life, contemplation and action, otium and negotium. Individuals are not the only ones to be involved in this mise en scène, in this reconfiguration of times. This change also addresses institutions, enterprises and so on. Social entities must create a script of their own biography, scenarios in which the "intimate sharing" legitimates the authenticity of their strategy. At the same time, big brands no longer offer simple products: They create whole lifestyles. The time of buying and of advertising is no longer delimited to a specific section of our life; it proliferates in each moment of our day.

The exposition of the most intimate aspects of our experiences, of our emotions and of our thoughts is carried through the sharing of pictures, vocal messages, videos, diversified forms of writing - messages, comments, emoticons, emojis. Our self-portraits (selfies), our visual biographies on Instagram, our ephemeral Snapchat videos enable a plural narration of the self. The names of the most successful sharing apps - Instagram, Snapchat - explicitly recall this ephemeral and short-timed dimension. Narration grasps the instant, it creates fragments of identity we can immediately spend, something we can share in a space that immediately buries them under the cascade of millions of similar posts.

The main feature of all these forms of communication is that they do not allow a stable and durable narration. They do not produce a substantial image of the self, a steady reflection of a stable personality; they rather offer the idea 
of an ever-evolving project, something adaptable according to the feedback it receives, and therefore something that can always be reformed and modified. These forms of "confession" do not expose an already formed self. The hypermodern I does not read its own history before someone else, be it another human or even God; it constantly rebuilds itself in a temporary and plural way. We build ourselves looking at ourselves, but we do it for someone else, we are produced and edited in order to have social and economical visibility.

In our age, we can no longer be naïve about the way we share the fragments of our life, we cannot do it without reflecting on the impact this sharing could have, and on its possible use by the others. The pictures we post on Facebook will be analyzed by the HR department of the agency we want to apply to before our interview, or they will contribute to determine our personality, our liabilities and our potentialities. All information about us becomes a profile that can be used to predict how we will behave. Without arriving at the extreme levels of countries like China, with their social credit system, it is true that the most private and intimate aspects of our life are acquiring more and more social relevance, and they have a decisive impact on our social and business life.

If we do not want to be reduced to what is visible, to our actions and to our words, to our affections and desires, then we have to reintegrate in our lives what the philosophical and theological tradition has called "interiority". Interiority is an act of resistance against the tendency to constantly stage our intimacy, to construct our own identities in a form of public narrative; it implies taking conscience of the political meaning of sharing. Again, this does not mean that we should create a private "mental space" that is inaccessible to technology and to society. It only means that we must develop social practices that grant us the possibility to keep various degrees of distance between individuals. ${ }^{22}$

If we recognize the tyrannical aspect of transparency, of authenticity and of visibility, then opacity, invisibility and secrecy appear as necessary elements in order to keep our individual and social balance. It is not sufficient to interpret these dimensions as simple "internal places" inside the soul. Secrecy and opacity are a fundamental aspect of the social practices inside every community.

22 Byung-Chul Han identified the absence of distance as the main consequence of the social implementation of digital media. See Han, In the Swarm, pp. 1-6. 
Otherness is the last feature we are going to discuss in order to provide a basic description of the human condition. Finitude also means openness to the other, but this openness is not set once and for all; its borders are shaped through our choices and through the technological setting we find ourselves in. As corporeity is the basis to understand interiority, interiority is the key aspect to understand the way we relate to each other.

We have said that digital technologies show us the social importance of interiority. Electronic architecture is the new cartography of our social space, where the distinction between work, entertainment, sexuality and family is constantly at risk. This new shape of our social space completely changes the nature of our social interactions.

A different architecture of the interior space is also a different way to look at others. Before the other had a "chamber of the heart", his true self was never completely taken for granted. No one could simply assume a complete transparency of the other. This opacity was the space where hospitality and dialogue were possible. Listening to the voice of the other means exposing ourselves to the risk of knowing something we do not want to know, to misunderstand, to find out something we do not like. This is also a chance for acceptance, for further reflection, for knowledge of something we had never known before.

The notion of "sacred" designated the relationship with otherness from the standpoint of interiority. The inner castle, the temple, the chamber had a sacred character. God visited these places, and we were invited to inhabit them with him. The inner space has always been the space of a dialogue: dialogue with the self and with God, but also dialogue with the Other. The relationship with the other from the standpoint of interiority is called intimacy. ${ }^{23}$ But intimacy is the opposite of transparency, or of perfect coincidence: we are intimate with someone when we recognize their otherness, not when we manage to transform them in something identical with us.

It looks like a paradox: How can our "inner space" be the stage when the dialogue with the Other happens? The paradox appears only if we keep understanding interiority as separated from exteriority, namely as a private and secret space only we manage and know about. On the contrary, if we grasp the social dimension of inner life, if we understand interiority as a social practice, 
its constitutive relation to the Other and to the environment immediately becomes visible. ${ }^{24}$

Our home, today, is a digitalized environment. Digital media is full of potentialities, but the business model underneath them privileges identity over difference, and immediacy over effort. Our social media tend to avoid any true encounter with otherness, and to enclose us in chambers - the so-called echo chambers - where everyone already thinks what we think. There is no difference between inner and social space, because the social space is already engineered to separate us based on our desires, opinions and opinions. In this way, intimacy can no longer take place, because it is a long process that requires effort in the discovery of difference. On the contrary, on social media our inner self is already shared in the simplified form of a list of topics and choices.

The efforts we have to make in order to open ourselves to the other are somehow delegated to the code. Algorithms work for us in order to turn what is opaque and difficult into something transparent and simple. In this new environment, there is no longer space for the unexpected. Introspection is done for us by a machine, and the complexity of self is turned into a profile. After that, our social space is engineered in order to fit this profile, in order to avoid any form of unwanted friction between us and what is external to us.

Digital media also create a digital memory palace, an exteriorized memory that never leaves us, and that interacts with us constantly suggesting what we should see, with whom we should talk, what we should buy, where we should go. The paradoxical consequence of this process is that our own interiority is external to us, it is no longer in our power: Our soul lives through the devices that depict our environment, but we have very little control over the way these prostheses shape our own self.

This exteriorized self has no space for oblivion: It collects all our data in the form of texts, pictures and videos, but also in the pure form of time and space: How long we do something, where we are, how many times we go somewhere. The app called Memories edits and organizes our own media, creating artificial recollections of our past.

If no oblivion is possible, we are unable to select what is important to us. In this way, any form of reticence in the dialogue with the other immediately become suspect. In an episode of the famous TV Series Black Mirror, written by Charlie Brooker and Jesse Armstrong, the authors imagine a world where technology makes it possible to archive and externalize individual memory in the

24 This will be a key aspect of our research. Christian theological tradition offers many different theoretical frameworks to understand the nature of interiority. Many of these constitute an alternative to the classical dualistic model. For an introduction see Rosenthal, Quelqu'un à Qui Parler. 
form of videos. These videos can be shared and played on any support, and are largely used to work out arguments, or to decide whether to hire someone or not. In the episode, the main character Liam (Toby Kebell) obsessively watches his own memories in order to detect strange behaviours by his girlfriend Fi (Jody Wittaker), and becomes more and more sure that she is cheating on him. In a world without oblivion, dialogue is no longer necessary: We have all the data, and anything more complex than a Yes/No question is a lie.

The great paradox of this new digital environment is that everything is basically insignificant, but nothing gets lost. Evanescence and permanence are two poles of the same dynamic. We have no chance to meditate, to rethink and rewrite our own experiences. This new digital hypermnesia makes it impossible to recur to traditional spiritual exercises, practices based on the plastic nature of memory and on the possibility to rewrite it with our imagination. Every kind of hermeneutical reflection over what we have done, again, is in principle a lie. In this way, otherness does not exist anymore in the form of a subject: true otherness is the digital space itself, its rules and its algorithms.

The flattening of social dynamics on the factual, namely on the possibility to check and show everything, entails the end of trust. But trust, just like faith, is an unavoidable aspect of human relations. There is no trust without opacity, and opacity entails contingency. "Do not swear by your head, for you cannot make even one hair white or black" (Mt 5, 37). The need for transparency is a need for certainty, the will to overcome our finite condition and be able to foresee the outcome of every action. The end of trust is also the end of desire. Social relations are more and more based on the interaction between overexposed personalities and bodies. We do not only know everything about the tastes, the thoughts and the fears of our neighbours: We also know their bodies.

In our hypersexualized society, bodies and minds are overexposed, but this exposition is not neutral: It is not the manifestation of some pre-formed reality underneath, but rather a process through which our personalities and our bodies are shaped and changed. This is why the overexposition of the self is a threat to the actual existence of otherness: If every aspect of ourselves is exposed and shaped by the rules of the public space and of our digital public environment, then everything is going to be modelled according to a standard, to a set of rules and of pre-set possible options.

Another paradox of hypermodern society is that it constantly pushes the individual to be "unique" by letting him choose amongst a pre-determined set of options, however vast this set may be. Otherness is tolerated only insofar as it is metabolized as a possible option: What cannot be recognized and indexed is not welcome. True otherness, what requires us to actually change ourselves in order to meet the other, and to put back in discussion the pillars 
of our existence in order to rebuild them in a new social context, is perceived as a danger.

Inner space is not a closed chamber; it is not a finished voyage of the self. As we said, inner life is not a way to cut everything else out, to escape from the external world. On the contrary, it is a way of meeting the world, of exposing ourselves to it.

Our digital home is a new manifestation of the need humans feel to know each other and themselves. It is a place of mutual and self-revelation. But what is revealed in this new space, and according to which modalities? The notion of revelation entails some sort of openness (as in the German word Offenbarung). It is not an obliteration of the mystery and of distance, but rather the institution of a bond with something that exceeds and that keeps exceeding, something we do not try to bring back in the safe space of our own territory. Christian Revelation shows us the radical alterity of God and - at the same time - His absolute proximity (through the Incarnation). Infinite and finite at the same time, God speaks to us in order to keep a conversation open, he invites us to share our life and live it together. ${ }^{25}$ Other doctrines and religions, of course, open to us different understandings of Revelation: In our world a theological anthropology of the Digital must keep an interreligious perspective.

In the digital cathedral ${ }^{26}$ a new relationship between closeness and openness is realized. On one side, the inner space is constantly exposed, visible and transparent; on the other side, any form of true openness is translated in the numeric language of digital space, a space where desires immediately find some form of satisfaction. The digital space is where the distance between question and answer is minimized, up to the vanishing point. It is structured as a place where map and territory seem to be the same, and where it seems impossible to be lost. In this new condition, in which the voice of our soul is constantly offered in streaming, how can we imagine ways to keep living the experience of questioning, desiring, exploring?

New forms of millennialism and of spiritualism are flourishing in this age at all levels of society, but the true question is not about the destiny of religion; it is about the destiny of humanity. If being humans means to entertain a relationship with our own corporeality, with our finitude, with alterity, then the question of a theological anthropology of the Digital - at the same

25 Vatican Council 2, Dogmatic Constitution Dei Verbum, n. 2.

26 The reference is to Raymond, The Cathedral and the Bazaar. 
time an existential and a political one - is the following: how to (re)think the overflowing richness of finitude in a digitalized world? The answer to this question can be given only by exploring the sets of critical practices that have been created in the social space and in the intellectual dimension in order to revoke in question the mainstream conception of digital technologies, of their meaning and of their possible use. In this sense, theological anthropology does not only look to the past, by retracing the genealogy of digital technologies and their originary connection to human finitude; it also looks to the future, by imagining new forms of possible interaction between humans and technology, and new ways to express our human finitude in our present digital environments.

For this reason, our task will be to follow the paths we have just sketched, and to analyze what we have recognized as the core concepts of theological anthropology - finitude, openness, creaturehood, interiority, otherness, revelation - using the instruments given to us by the history of theology. It is an incredibly complex and rich history, able to offer us brand new ways to look at reality and ourselves. It is a treasure we mush cherish and keep investigating in order to fully express the depth and width of the theological gaze, and to gain a new understanding of our human condition and of our place in a digitalized world.

\section{Acknowledgement}

The research activity that led to the realization of this paper was carried out within the Department of Excellence Project of the Department of Philosophy and Educational Sciences of the University of Turin.

\section{Biography}

Gemma Serrano is Professor of Theology at the Faculty of Notre Dame (Collège des Bernardins, Paris), where she also directs the research department "Humanisme numérique". Her research interests focus on the affective dimension of digital culture, on the relationship between theology and technology and on the theological sources of contemporary technological imaginaries.

Alessandro De Cesaris is post-doc research fellow in Theoretical Philosophy at the University of Turin and visiting research fellow at the Collège des Bernardins. His research interests focus on classic german philosophy, philosophy of technology and media theory. 


\section{Bibliography}

Agamben, Giorgio: The Open. Man and Animal. Stanford, CA: Stanford University Press, 2004.

Anders, Günther: Die Antiquiertheit des Menschen. Über die Seele im Zeitalter der zweiten industriellen Revolution. München: Beck, 2002.

Assman, Jan: Achsenzeit. Eine Archäologie der Moderne. München: Beck Verlag, 2018.

Bellah, Robert/Joas, Hans (eds.): The Axial Age and Its Consequences. Cambridge, MA: Harvard University Press, 2012.

Bertram, Georg W.: Two Conceptions of Second Nature, in: Open Philosophy 3 (1/2020), pp. 68-8o.

Cukier, Kenneth/Meyer-Schönberger, Viktor: Big Data. A Revolution that will Transform how we Live, Work and Think. New York, NY: Harcourt Publishing, 2013. Doueihi, Milad: La Grande Conversion Numérique. Paris: Points, 2011.

Esposito, Roberto: A Philosophy for Europe. From the Outside. New York, NY: Polity Press, 2018.

Esposito, Roberto: Living Thought. The Origins and Actuality of Italian Philosophy. Redwood City, CA: Stanford University Press, 2012.

Fairhurst, Michael: Biometrics. A Very Short Introduction. Oxford: Oxford University Press, 2018.

Floridi, Luciano: The 4th Revolution. How the Infosphere is Reshaping Human Reality. Oxford: Oxford University Press, 2017.

Gehlen, Arnold: Man: His Nature and Place in the World. New York, NY: Columbia University Press, 1998.

Han, Byung-Chul: In the Swarm. Digital Prospects. Cambridge, MA: MIT Press, 2017.

Harari, Yuvah Noal: Homo Deus. A Brief History of Tomorrow. London: Harvill Secker, 2016.

Havelock, Eric A.: The Muse Learns to Write. Reflections on Orality and Literacy from Antiquity to the Present. New Haven, CT: Yale University Press, 1986.

Illich, Ivan: Deschooling Society. New York, NY: Penguin Books, 1971.

Jaspers, Karl: Origin and Goal of History. New Haven, CT: Yale University Press, 1953.

Jones, Lynette: Haptics. Cambridge, MA: MIT Press, 2018.

Jourdain, Édouard: Théologie du capital. Paris: PUF 2021.

Jullien, François: De l'intime. Loin du bruyant amour. Paris: Grasset, 2013.

Kurzweil, Ray: The Singularity is Near. When Humans transcend biology. New York, NY: Penguin Books, 2005.

Lanier, Jaron: The Dawn of the New Everything. A Journey into Virtual Reality. New York, NY: Penguin Books, 2018.

Marx, Leo/Smith, Merrit Roe: Does Technology Drive History? The Dilemma of Technological Determinism. Cambridge, MA: MIT Press, 1994. 
Madrigal, Alexis C.: Zuckerberg's Dream: Everyone Sitting in One Room (Controlled By Invisible Forces), https://www.theatlantic.com/technology/archive/2013/12/zucker bergs-dream-everyone-sitting-in-one-room-controlled-by-invisible-forces/282342/ (date of last access: 17.08.2020).

Neff, Gina/Dawn, Nafus: Self-Tracking. Boston, MA: MIT Press, 2016.

O'Connell, Mark: Notes from an Apocalypse. A Personal Journey to the End of the World and Back. New York, NY: Doubleday, 2020.

O'Connell, Mark: To be a Machine. Adventures among Cyborgs, Utopians, Hackers, and the Futurists Solving the Modest Problem of Death. London: Granta, 2017.

Ong, Walter J: Orality and Literacy. The Technologizing of the Word. New York, NY: Routledge, 1982.

Plessner, Helmuth:Anthropologie der Sinne, in: Gesammelte Schriften, II I. Frankfurt am Main: Suhrkamp Verlag, 198o.

Portinaro, Pier Paolo: Le mani su Machiavelli. Una critica dell' 'Italian Theory'. Roma: Donzelli, 2018.

Raymond, Erik S.: The Cathedral and the Bazar. New York, NY: O'Reilly Media, 2001.

Rosenthal, Viktor: Quelqu'un à Qui Parler. Une histoire de la voix intérieure. Paris: PUF, 2019.

Seminar 'Habiter', organized by Louise Merzeau at the Collège des Bernardins, Paris, in 2015 .

Simondon, Gilbert: Du Mode d'Existence des Objets Techniques. Paris: Aubier, 1958.

Simondon, Gilbert: Sur la Technique. Paris: Puf, 2014.

Stiegler, Bernard:Technics and Time r:The Fault of Epimetheus. Stanford (CA): Stanford University Press, 1998.

Taylor, Charles: The Language Animal. The Full Shape of the Human Linguistic Capacity. Cambridge, MA: Harvard University Press, 2016.

Vattimo, Gianni: The Transparent Society. Baltimore, MD: John Hopkins University Press, 1992. 